УДК 532.6

\title{
ВЛИЯНИЕ ФИЗИЧЕСКИХ УСЛОВИЙ НА ВЛАГОПЕРЕНОС С ПОВЕРХНОСТИ ЛЬДА ПО ДИСПЕРСНОЙ СРЕДЕ ПРИ ОТРИЦАТЕЛЬНЫХ ТЕМПЕРАТУРАХ
}

\author{
(C) 2018 В. И. Егочина, Г. Д. Копосов, А. В. Тягунин \\ Северный (Арктический) федеральньий университет имени М. В. Ломоносова, \\ наб. Северной Двины, 17, 163002 Архангельск, Россия \\ e-mail: egochina.vi@mail.ru
}

Поступила в редакцию 27.11.2018

\begin{abstract}
Аннотация. Целью описанных в работе исследований была проверка возможности использования поверхности льда в качестве генератора влаги при измерениях влагопроводности грунтов. В работе представлены результаты исследования влияния различных физических условий на влагоперенос лед - дисперсная среда при отрицательных температурах, таких как: градиент температуры по направлению влагопереноса, действие гравитационного поля, наличие примесей во льду.
\end{abstract}

Ключевые слова: влагоперенос, градиент температуры, гравитационное действие, песок, лед, квазижидкий слой.

DOI: https://doi.org/10.17308/kcmf.2018.20/634

\section{ВВЕДЕНИЕ}

Среди многообразия мерзлых пород наиболее сложным объектом исследования являются дисперсные породы. Вода в них обычно находится в трех агрегатных состояниях: льда, пара и незамерзшей воды. Количество переохлажденной воды в мерзлых и промерзающих грунтах принято называть «незамерзшая вода» [1-3], которая представляет собой часть связанной воды, содержание которой уменьшается с понижением отрицательной температуры. Лед и незамерзшая вода находятся постоянно в динамическом равновесии. Молекулы незамерзшей воды подвижны и определяют такое свойство, как влагопроводность. Оно определяет перенос влаги в мерзлых грунтах в направлении убывания потенциала частиц [4]. Наибольший интерес в области геокриологии в настоящее время представляют вопросы миграции связанной и капиллярной воды и пара, от которых зависит решение ряда задач в области грунтоведения, инженерной геологии, почвоведения и геокриологии [5-9]. Проводились работы по изучению процесса зарождения льда в поровом пространстве влагосодержащих грунтов $[10,11]$, работы по изучению влияния степени водогазонасыщения на температурные де- формации мерзлых грунтов [12]. Особенность процесса замерзания воды в мерзлом грунте состоит в неодновременности фазового перехода воды в пределах близкорасположенных участков его порового пространства. С термодинамической точки зрения причиной миграции воды и пара в мерзлых грунтах является неравновесное состояние системы «грунт-влага». Влагоперенос в мерзлых грунтах обусловлен с термодинамической позиции действием градиентов поверхностной энергии, осмотического давления, температуры, электрического и других потенциалов.

В физике почв для описания движения влаги применяют термин «фильтрация». При описании процесса считается, что вода по всем порам движется с одинаковой скоростью. Но равномерное движение влаги встречается в природе не часто, в основном в периоды весеннего снеготаяния, верховодки, при движении грунтовых вод. Движение воды в насыщенной почве описывается законом Дарси. В работах $[13,14]$ приведены виды фильтрации; коэффициенты фильтрации для различных по своему характеру и природе почв; выделены две стадии поглощения воды почвой - стадия впитывания, при котором происходит быстрое поглоще- 
ние воды в ненасыщенную влагой почву, и стадия водопроницаемости - движение воды в насыщенной почве.

С появлением компьютерной томографии появилась возможность обследовать мерзлые и промерзающие породы и почвы для решения физических, биологических, химических и геологических задач $[15,16]$. Были проведены исследования криогенных элементов строения образцов почв при промерзании [17].

Но на данный момент все методы определения незамерзшей воды являются трудоемкими. В работе $[18,19]$ предложен ускоренный метод оценки содержания незамерзшей воды в мерзлых грунтах. Методика эксперимента заключается в определение активности поровой воды при положительной (комнатной) температуре с последующим термодинамическим пересчетом на зависимость содержания незамерзшей воды от отрицательной (по Цельсию) температуры.

Таким образом, можно выделить ряд основных недостатков при исследовании мерзлых грунтов:

- отсутствие математических моделей влагоперехода в грунт;

- несовершенство методик измерений, которые проводятся при наличии градиента температур без учета его влияния в температурном диапазоне от +0.5 до $-10{ }^{\circ} \mathrm{C}$, т. е. рассматриваются промерзающие и оттаивающие грунты, в которых уже существует жидкая фаза;

- не учитывается фаза предплавления льда;

- не рассматривается действие гравитационного поля на влагоперенос;

- малый диапазон температур.

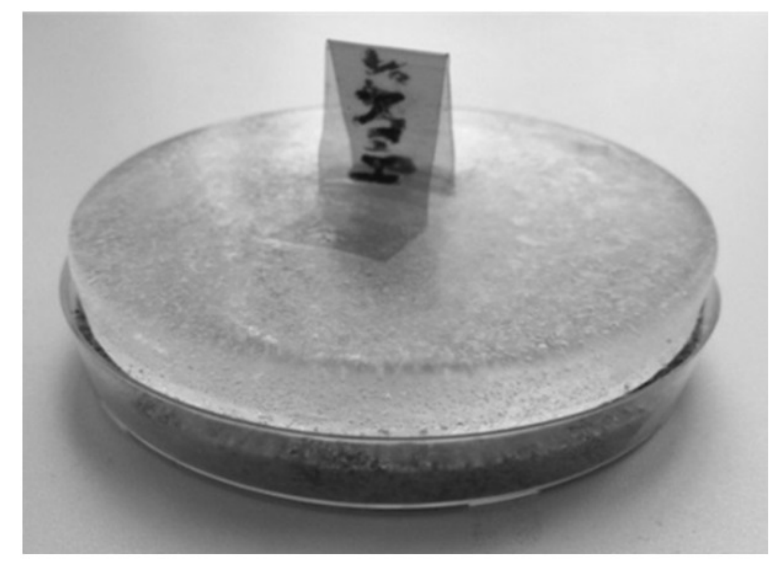

$a$
Авторами работы [20] в лаборатории физики дисперсных систем был обнаружен процесс стекания квазижидкого слоя по поверхности льда и выявлено, что такой слой на поверхности льда при времени восстановления в 85 секунд является генератором влаги в дисперсную среду при отрицательных температурах [21]. Для развития теории влагопереноса с поверхности льда в дисперсную среду при отрицательных температурах, необходимо знать, от каких физических условий зависит этот процесс.

Цель работы - изучение влияния физических условий (наличие примесей во льду, направление гравитационного поля и градиента температуры, наличие разных дисперсных сред), а так же общих особенностей (временная динамика и распределение влаги по глубине образца) на влагоперенос лед - дисперсная среда при различных температурах. Диапазон температур был выбран от -5 до $-24{ }^{\circ} \mathrm{C}$ (по техническим возможностям морозильной камеры).

Для изучения влагопереноса с поверхности льда исследовались следующие образцы дисперсной среды: речной песок, силикагель, белая сажа БС-50, каолиновая (белая) глина.

\section{ЭКСПЕРИМЕНТАЛЬНАЯ ЧАСТЬ}

Исследования проводились с помощью весового способа. При весовом методе в качестве измерительной ячейки использовалась чашка Петри диаметром 9.6 см. Внешний вид представлен на рис. 1. Ячейка засыпалась порошком разных веществ, глубина засыпки составляла порядка 9 мм, и охлаждалась сутки в морозильной камере с автоматическим поддержанием температуры. Для регу-

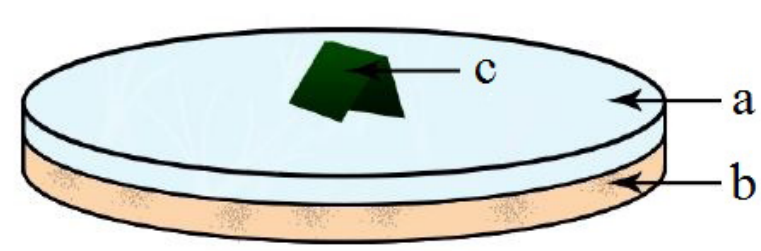

$b$

Рис. 1. Внешний вид ячейки $(a)$ и схематичное изображение установки $(b)$, где $a$ - ледяная пластина; $b-$ песок; $c$ - держатель, утопленный в лед

[Fig. 1. The appearance of the cell $(a)$ and the schematic picture of the installation $(b)$, where $a-$ the ice plate; $b$ - sand; $c$ - holder, recessed into ice] 
лировки и контроля температуры морозильная камера была оснащена термодатчиком. Погрешность датчика составляет $0.1^{\circ} \mathrm{C}$. Заранее была изготовлена ледяная пластина, совпадающая по диаметру с ячейкой. Через сутки ледяная пластина, охлажденная до выбранной температуры, помещалась на образец, и начинался отчет времени эксперимента. Ежедневно измерялся прирост массы образца.

\section{РЕЗУЛЬТАТЫ И ИХ ОБСУЖДЕНИЯ}

\section{Исследование временной динамики}

Для изучения временной зависимости перехода влаги с поверхности льда в песок и влагопереноса был проведен эксперимент при различных температурах [21]. Результат эксперимента при температуре $-5{ }^{\circ} \mathrm{C}$ представлен на рис. 2 , длительность эксперимента составила 100 часов.

На графике следует выделить две фазы протекания процесса влагопереноса в грунт: область с резким возрастанием влаги до предельного значения и квазилинейную область. Первая область временной динамики влагопереноса описывается следующим уравнением:

$$
\Delta m=\Delta m_{\text {пр }}\left(1-e^{-\lambda t}\right),
$$

где $\Delta m_{\text {пр }}$ - предельное значение массы связанной воды, покрывающей равномерно гранулы дисперсной среды; $\lambda$ - показатель интенсивности влагопоглощения грунта, связан с коэфициентами поверхностного натяжения на границах гранула-вода, вода - воздух и вода - лед, (1/час); $\Delta m$ - изменение массы воды, перешедшей в дисперсную среду, $t$ - время. Уравнение (1) получается путем решения дифференциального уравнения (2) переноса влаги:

$$
d m=\lambda\left(m_{\text {пр }}-m\right) d t .
$$

Для влажности, уравнение (1) приводится к следующему виду:

$$
W=W_{\text {пр }}\left(1-e^{-\lambda t}\right),
$$

где $\frac{\Delta m}{m}=W, W$ - влажность в момент времени $t$, $W_{\text {пр }}$-предельное значение влажности, достигнутое в первой фазе.

Представим (3) в логарифмической форме:

$$
\ln \left(1-\frac{W}{W_{\text {пр }}}\right)=-\lambda t
$$

Величину $W_{\text {пр }}$ можно определить по точке перехода к квазилинейной зависимости. Скорость изменения влажности: $\frac{d W}{d t}=W_{\text {пр }} \lambda e^{-\lambda t}$. Тогда $\ln \frac{d W}{d t}=\ln W_{\text {пр }}+\ln \lambda-\lambda t$, взяв полиноминальное представление $W=f(t)$, можно найти $\frac{d W}{d t}=f(t)$ и после этого построив линейную зависимость:

$$
\ln \frac{d W}{d t}=\left(\ln W_{\text {пр }}+\ln \lambda\right)-\lambda t
$$

находим $\ln W_{\text {пр }}, \ln \lambda$ и соответственно $W_{\text {пр }}$. Используя линейную аппроксимацию, появляется возможность найти $\lambda$.

Данный способ нахождения $W_{\text {пр }}$ дает возможность проверки уравнения (4). На рис. 3 представлена проверка данного соотношения для белой глины при различных температурах.

Используя линейную аппроксимацию, появляется возможность найти $\lambda$. В табл. 1 представлены

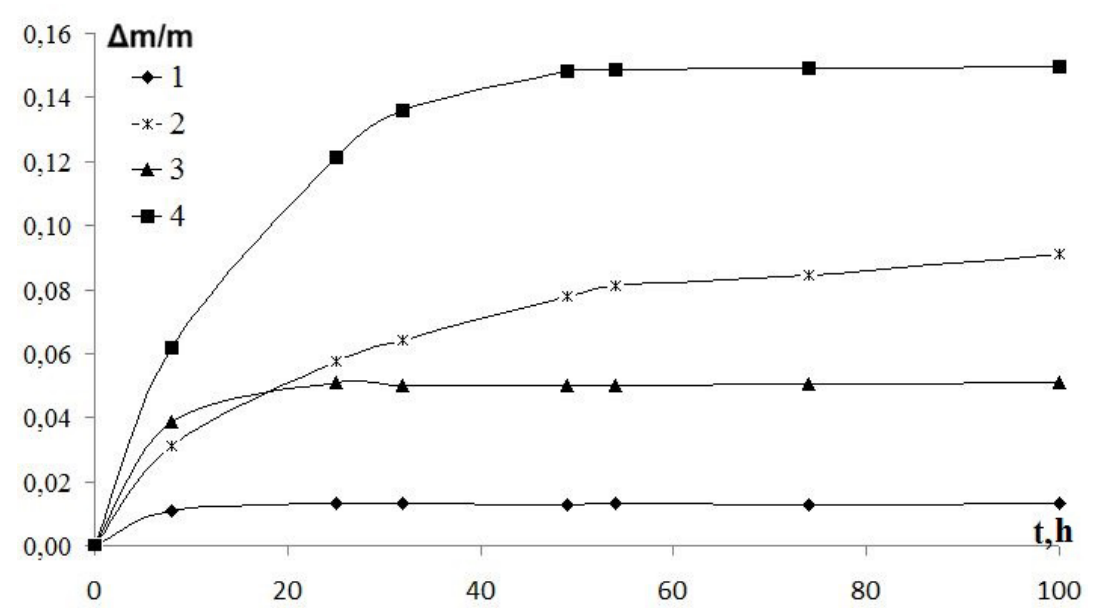

Рис. 2. Временная зависимость влагоперехода лед - дисперсная среда при температуре $-5{ }^{\circ} \mathrm{C}$; речной песок (1), каолиновая (белая) глина (2), белая сажа БС-50 (3), силикагель (4)

[Fig. 2. The time dependence of the moisture transition is ice - a dispersed medium at a temperature of $-5{ }^{\circ} \mathrm{C}$; river sand (1), kaolin (white) clay (2), carbon white (3), silica gel (4)] 


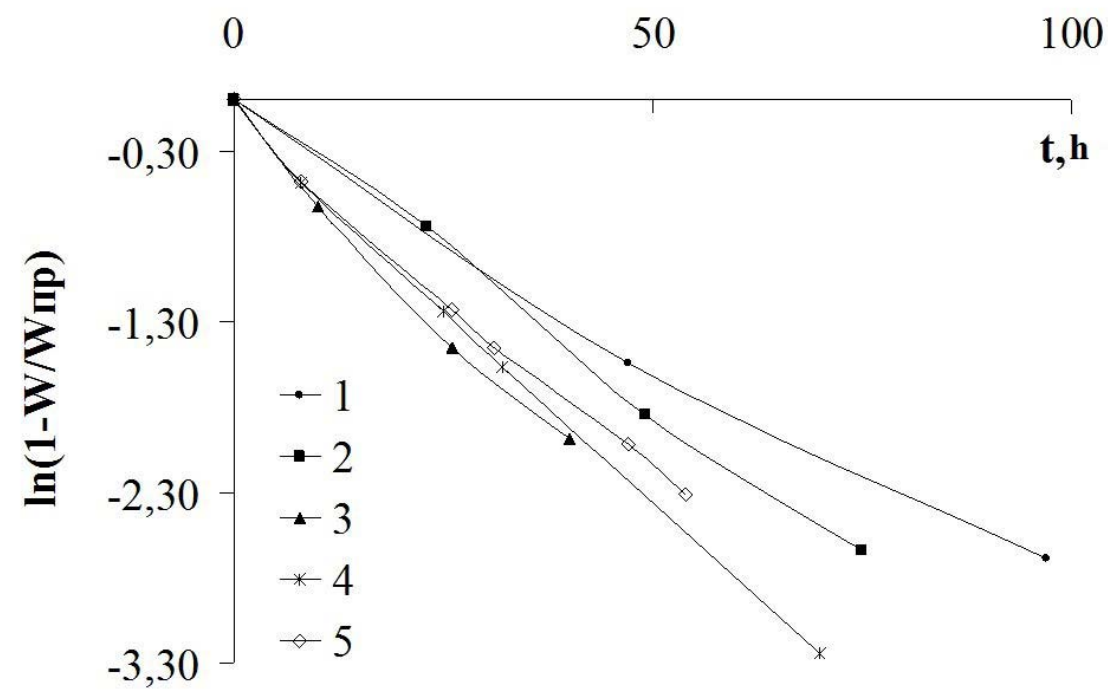

Рис. 3. Проверка формулы (4) для белой глины при температурах: -14 (1), -10 (2), -7 (3), -5 (4) и -3 (5) ${ }^{\circ} \mathrm{C}$

[Fig. 3. Checking the formula (4) for white clay at temperatures: $-14(1),-10(2),-7(3),-5(4)$ и $\left.-3(5){ }^{\circ} \mathrm{C}\right]$

обработанные результаты статьи [21]; приведены сравнительные значения вероятности перехода молекул воды в порошок дисперсной среды (ДС) при различных температурах эксперимента.

Чем больше температура, тем больше вероятность того, что молекулы воды смогут перейти в большем объеме в грунт. Материалы, представленные в таблице, имеют достаточно высокую скорость влагопереноса.

Во второй фазе перенос влаги происходит по незамерзшей пленке воды [4]. Из описанных далее экспериментов следует, что движущей силой потока влаги выступают: гравитационное действие, градиент температуры и градиент концентрации.

\section{Исследование распределения влажности по глубине}

По окончании эксперимента была определена глубина проникновения влаги и влажность каждого слоя: образец делился на 6 частей по высоте, примерно по 1 мм каждый, и высушивался в тепловой камере. На рис. 4 представлено распределение влаги по глубине белой глины при температуpe $-5{ }^{\circ} \mathrm{C}$ и проверка уравнения (11) представленного далее.

Распределение влаги по глубине имеет вид: $W_{h}=W_{0} e^{-\alpha h}$, где $h-$ это высота выбранного слоя. Учитывая фактор накопления влаги внизу ячейки, необходимо отнять минимальную влажность образца $W_{\min }$, полученную после распределения. С учетом наличия минимальной влажности и при стремлении глубины ячейки к бесконечному значению, получаем: $W_{h}-W_{\min }=\left(W_{0}-W_{\min }\right) e^{-\alpha h}$. Проверка данного уравнения представлена на рис. $4 b$.

Первый слой имеет максимум влажности, так как он непосредственно соприкасался со льдом, далее наблюдаем уменьшение влаги по образцу до 3 слоя, что соответствует 6 мм по высоте ячейки. Представим распределение поглощенной влаги

Таблица 1. Величины $\lambda$ в различных порошках ДС

[Table 1. Values $\lambda$ at the various powders dispersed medium]

\begin{tabular}{|c|c|c|c|c|c|}
\hline & \multicolumn{5}{|c|}{$\lambda(1 /$ час $)[1 / \mathrm{h}]$} \\
\cline { 2 - 5 } & $t=-14^{\circ} \mathrm{C}$ & $T=-10^{\circ} \mathrm{C}$ & $t=-7{ }^{\circ} \mathrm{C}$ & $t=-5^{\circ} \mathrm{C}$ & $t=-3^{\circ} \mathrm{C}$ \\
\hline $\begin{array}{c}\text { Силикагель } \\
\text { [Silica gel] }\end{array}$ & 0.0190 & 0.0628 & 0.0579 & 0.0749 & 0.1225 \\
\hline $\begin{array}{c}\text { Белая (каолиновая) глина } \\
\text { [Каolin (white) clay] }\end{array}$ & 0.0276 & 0.0360 & 0.0554 & 0.0627 & 0.0417 \\
\hline $\begin{array}{c}\text { Белая сажа БС-50 } \\
\text { [Carbon white] }\end{array}$ & 0.0034 & 0.0294 & 0.5325 & 0.1805 & 0.0627 \\
\hline $\begin{array}{c}\text { Песок } \\
\text { [River sand] }\end{array}$ & 0.0117 & 0.0113 & 0.5366 & 0.2271 & 0.1733 \\
\hline
\end{tabular}




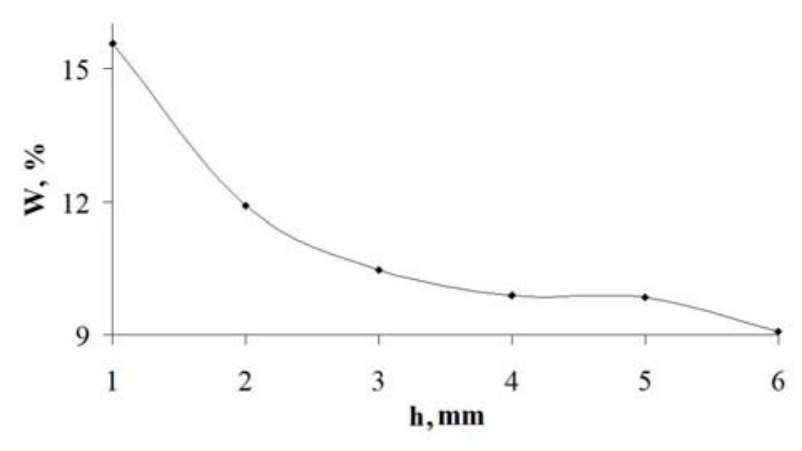

$a$

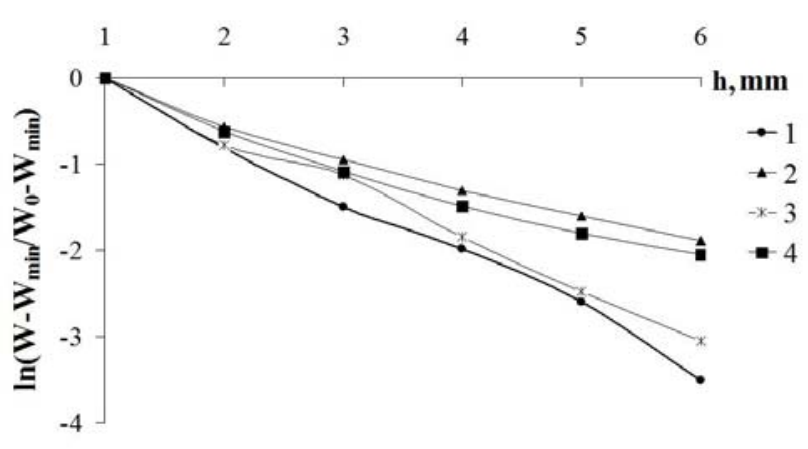

$b$

Рис. 4. Распределение влаги по глубине слоя для белой глины $(a) ;(b)$ проверка уравнения для белой глины при температурах: -14 (1), -7 (2), -5 (3) и -3 (4) ${ }^{\circ} \mathrm{C}$

[Fig. 4. The moisture distribution in the depth of the layer for white clay $(a) ;(b)$ checking the formula for white clay at temperatures: $-14(1),-7(2),-5(3)$ и $\left.-3(4){ }^{\circ} \mathrm{C}\right]$

образцом. Интенсивность потока влаги $J=\frac{d m_{\text {прош }}}{S \cdot d t}$ при прохождении слоя $d x$ грунта:

$$
J_{\text {прошा }}=J_{\text {вх }}-d J \text {, }
$$

где $d J$ - изменение интенсивности, связанное с переходом влаги в поры и с переходом в свободное состояние и последующим замерзанием. Допустим, что $d J=\alpha \cdot J_{\text {вх }} \cdot d x$, где $\alpha=\frac{d J}{J_{\text {вх }} \cdot d x}$. Тогда уравнение (6) преобразуется:

$$
J_{\text {прош }}=J_{\text {вх }}-\alpha \cdot J_{\text {вх }} d x,
$$

В этом случае закон убывания потока становится подобным закону Бугера:

$$
J(x)=J_{0} e^{-\alpha x},
$$

где $J_{0}$ - поток на нулевом уровне глубины, $x$ - глубина слоя вещества, $\alpha-$ коэффициент поглощения влагопотока. Соответствующая поглощенная интенсивность: $J_{0}-J(x)=J_{0}\left(1-e^{-\alpha x}\right)$. Применим данную закономерность на переносимую массу воды:

$$
d m_{\text {погл }}=d t \cdot S \cdot \alpha \cdot J_{0} e^{-\alpha x} d x .
$$

После дифференцирования уравнения (9) получаем:

$$
\Delta m_{\text {погл }}=S \cdot \alpha \cdot J_{0} \int_{0}^{\tau} d t \cdot \int_{0}^{x} e^{-\alpha x} d x=S \cdot J_{0} \tau \cdot e^{-\alpha x} .
$$

Таким образом, $\Delta m_{\text {погл }}=\Delta m_{0} e^{-\alpha x}$. Проверка этого условия:

$$
\ln \frac{\Delta m_{\text {поглл }}}{\left(\Delta m_{0}\right)_{\text {погл }}}=-\alpha x .
$$

И это позволяет определить значение $\alpha$ при размерности $[\alpha]=\frac{1}{\mathrm{MM}} ; \frac{1}{\mathrm{~cm}} ; \frac{1}{\mathrm{M}}$.

\section{Исследование влияния примесей во льду}

В природе лед всегда содержит некоторое количество примеси, поэтому актуальной стала задача о выяснении влияния примесей во льду на влагопереход. Были проведены исследования с примесями $\mathrm{NaOH}, \mathrm{NaCl}, \mathrm{KCl}$ и $\mathrm{KOH}$ при различных весовых концентрациях (\%): $3.5 ; 1 ; 0.1 ; 0.01$ и 0.001. Максимальная концентрация соответствует морской воде по $\mathrm{NaCl}$. Эксперимент проводился весовым методом. Для обеспечения однородности распределения примеси во льду заморозка льдинки осуществлялась послойно по 0.5 мм. Толщина льдинки была 1 см, а таких слоев - порядка 20.

Показателем эффективности $\eta$ действия примеси на влагоперенос является отношение массы воды, поглощенной дисперсной средой при наличии примеси $\Delta m(C)$, к поглощенной влаге в отсутствии примеси $\Delta m(0)$ :

$$
\eta=\frac{\Delta m(C)}{\Delta m(0)} .
$$

Зависимость показателя эффективности действия примеси во льду от самой примеси можно представить следующим сравнительным рядом: $\eta(\mathrm{KCl})>\eta(\mathrm{KOH})>\eta(\mathrm{NaCl})>\eta(\mathrm{NaOH})$.

Причина возрастания влагопереноса связана с уменьшением поверхностного натяжения $\sigma$ и соответственно увеличению вероятности перехода:

$$
w=\exp \left(-\frac{\sigma \cdot S}{k T}\right),
$$

где $S$ - площадь сечения объема молекулы воды.

Наличие соли, особенно при значениях концентрации более $1 \%$, способствует процессу перехода воды со льда в песок по причине уменьшения коэффициента поверхностного натяжения. По результатам исследования можно сделать вывод, что 
присутствие соли активизирует процесс влагопереноса в дисперсной среде.

\section{Исследование влияния направления гравитационного поля}

Для изучения влияния действия гравитационного поля на влагоперенос было заготовлено две измерительные ячейки. В первой ячейке лед располагался над образцом, и поток влаги совпадал с направлением гравитационного поля. Во второй ячейке ледяная пластина была закреплена под образцом, в данном случае действие гравитационного поля препятствовало процессу влагопереноса с поверхности льда.

Рис. 5 иллюстрирует процесс влагопереноса при различном положении ледяной пластины для порошка силикагеля.

При положении льда сверху образца происходит накопление влаги в образце, гравитационное поле способствует потоку воды с поверхности льда. При положении льда под образцом масса образца сначала возрастает по причине градиента поверхностной энергии, а затем начинает убывать, что возможно связано с диффузией паров воды и движением водной пленки в результате стекания под действием гравитационного поля.

Молекулы $\mathrm{H}_{2} \mathrm{O}$ перемещаются под действием гравитационного поля прыжковым образом, как и в обычной воде. Число прыжков по направлению гравитационного поля $n_{\uparrow \uparrow}=\frac{1}{6} n_{0} v e^{\frac{m g \delta}{k T}}$ и против гравитационного поля $n_{\uparrow \downarrow}=\frac{1}{6} n_{0} v e^{-\frac{m g \delta}{k T}}$. Здесь $m$-масса молекулы, $\delta$ - длина прыжка молекулы, $n_{0}$ - концентрация молекул $\mathrm{H}_{2} \mathrm{O}, \mathrm{v}$ - частота колебаний.

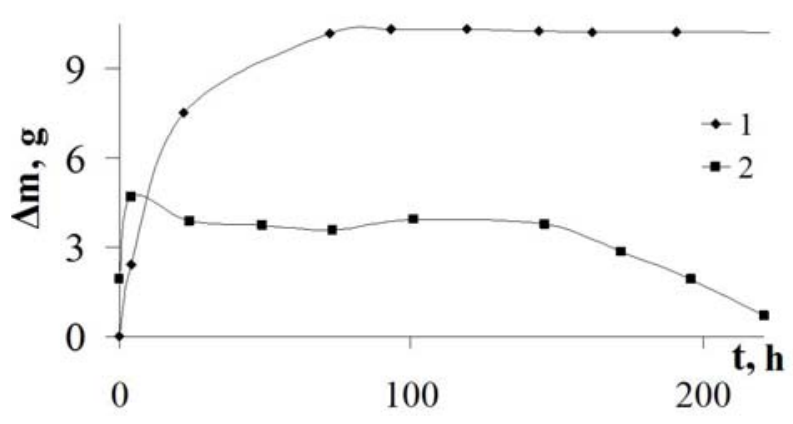

Рис. 5. Действие гравитационного поля при температуре $-5{ }^{\circ} \mathrm{C}$; лед сверху (1), лед снизу (2) образца

[Fig. 5. The influence of the gravitational field at a temperature of $-5^{\circ} \mathrm{C}$; ice above (1), ice below (2) of the sample]
Различие $n_{\uparrow \uparrow}$ и $n_{\uparrow \downarrow}$ порождает поток молекул в направлении гравитационного поля:

$$
\Delta n=\frac{1}{6} n_{0} \mathrm{v}\left(e^{\frac{m g \delta}{k T}}-e^{-\frac{m g \delta}{k T}}\right)=\frac{1}{3} n_{0} \mathrm{v} \cdot \mathrm{Sh}\left(\frac{m g \delta}{k T}\right),
$$

где $\mathrm{Sh}$ - гиперболический синус.

$$
\text { Для случая малости } m g \delta<k T: \Delta n=\frac{n_{0} v \cdot m g \delta}{3 k T} \text {. }
$$

Это приводит к разнице масс:

$$
\Delta m_{g}=\frac{n_{0} v \cdot m^{2} g \delta}{3 k T} \cdot S t .
$$

\section{Исследование влияния градиента температуры}

Все исследования, проведенные ранее, проводились в изотермических условиях. В связи с этим, было решено провести эксперимент по изучению влияния температурного градиента на влагоперенос. Измерительные ячейки были оборудованы нагревательным элементом с целью изменения температуры по направлению влагопереноса. Одна ячейка не содержала нагревательного элемента и выступала в качестве контрольной. С помощью медь-константановой термопары измерялась разница температур в ячейке, и одна термопара размещалась на границе лед-песок. Измерения прироста массы проводились весовым методом. Также были получены показания термоэдс термопары, силы тока и напряжения. Используя несколько значений тока подогрева, были выявлены зависимости, изображенные на рис. 6. Эксперимент проходил в три этапа при разном значении тока подогрева. На первом этапе ток подогрева составил 60 мА; на втором этапе спустя 240 часов и до 460 часов ток был уменьшен в 1.5 раза до зна-

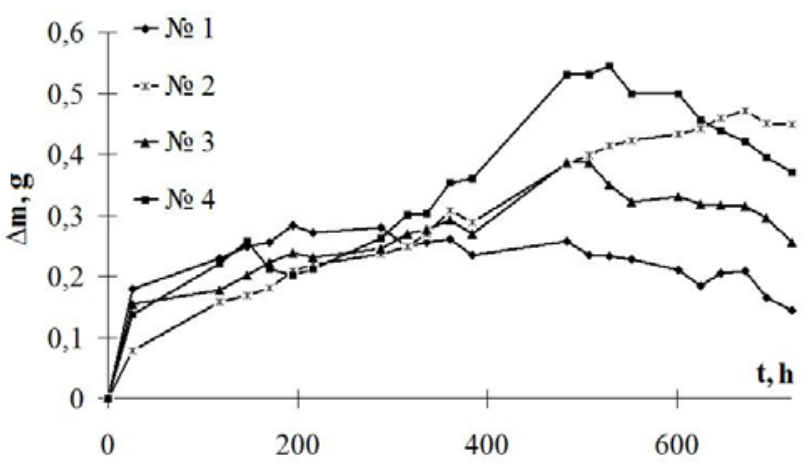

Рис. 6. Влияние градиента температуры при влагопереносе лед-песок при температуре $-5{ }^{\circ} \mathrm{C}$

[Fig. 6. Influence of temperature gradient at ice-sand moisture transfer at $-5^{\circ} \mathrm{C}$ ] 
чения 45 мА, и наблюдался спад прироста массы в образце; на третьем этапе в период после 720 часов при значении тока 90 мА происходил синхронный спад на всех ячейках. Задержка в показаниях прироста массы после изменения величины тока подогрева объясняется установлением термодинамического равновесия.

Причина наблюдаемого эффекта связана с температурной зависимостью коэффициента поверхностного натяжения. Градиент температуры вызывает термокапиллярный поток влаги интенсивности $J \sim \frac{d \sigma}{d T}$.

Эффект подсушивания образца обусловлен несколькими причинами. Первая причина связана с температурной зависимостью коэффициента поверхностного натяжения $\sigma$ (термокапиллярный эффект). Поток в этом случае согласно [22]:

$$
\frac{\Delta m_{\sigma}}{\Delta t \cdot S}=\frac{p h}{2 \eta}\left(\frac{d \sigma}{d T}\right) \frac{d T}{d x},
$$

где $p$ - плотность, $h$ - толщина пленки, здесь $\eta$ - коэффициент вязкости. Так как $\frac{d \sigma}{d T}<0$, то $\frac{\Delta m_{\sigma}}{\Delta t \cdot S}<0$ при градиенте температуры $\frac{d T}{d x}>0$.

Вторая причина связана с температурной зависимостью коэффициента диффузии $D$ :

$$
\frac{\Delta m_{\Delta T}}{\Delta t \cdot S}=\frac{\partial D}{\partial T} \cdot \frac{\partial T}{\partial x} \cdot \frac{d m}{d x} .
$$

Учитывая, что $D=D_{0} e^{-\frac{\Delta W}{k T}}$ получаем:

$$
\frac{\Delta m_{\Delta T}}{\Delta t \cdot S}=-\frac{\Delta W}{k T^{2}} D_{0} e^{-\frac{\Delta W}{k T}} \frac{\partial T}{\partial x} \cdot \frac{d m}{d x} .
$$

Здесь $\Delta W$ - энергия активации диффузного перемещения.

Третья из возможных причин связана с подплавлением льда и изменением в последнем уравнении $\frac{d m}{d x}$ и, кроме этого, с изменением $h$ в уравнении для $\frac{\Delta m_{\sigma}}{\Delta t \cdot S}$.

Эксперименты показали, что небольшой градиент температур по направлению влагопереноса способствует замедлению скорости перехода через песок. Это позволяет сделать вывод, что при создании определенного градиента температуры влагоперенос осуществляется в обратном направлении к контакту лед-песок, происходит сушка образца. Такая градиентная сушка имеет техническое применение при сушке древесины.

\section{ВЫВОДЫ}

- Обнаружена двухступенчатость временной динамики проникновения влаги с поверхности льда в грунт.

- Получено математическое уравнение, описывающее изменение влагопоглощения от времени, происходящего по причине действия поверхностных сил при покрытии поверхности гранул пленкой связанной воды.

- Выявлена особенность распределения по глубине поглощенной образцом массы при миграции влаги.

- Установлено влияние примеси солей и щелочей во льду на скорость миграции влаги, что связанно с их воздействием на коэффициент поверхностного натяжения.

- Исследовано действие градиента температуры, направленного вдоль потока влаги, на влагоперенос. Высказано предположение о наличии двух причин влияния градиента на интенсивность влагопереноса: температурной зависимости коэффициентов поверхностного натяжения и диффузии. Было выяснено, что при достижении определенного градиента температуры наблюдается перенос влаги к холодному концу, что позволяет управлять величиной и направлением переноса влаги;

- Изучена роль гравитационного поля при миграции влаги.

\section{СПИСОК ЛИТЕРАТУРЫ}

1. Novikov E. A., Shkuratnik V. L. Oshkin R. O. // Earth's Cryosphere, 2016, vol. 20, № 1, pp. 91-94. URL: http://www.izdatgeo.ru/pdf/earth_cryo/2016-1/91_eng.pdf

2. Anderson D. M. The Interface Between Ice and Silicate Surface. CRREL, USA, March 1967, 31 p.

3. Kozlowski T. // Cold Regions Sci. and Technol., 2016, № 122, pp. 18-25. DOI: https://doi.org/10.1016/j.coldregions.2015.10.009

4. Ершов Э. Д. Общая геокриология. Учебник. М.: Изд-во МГУ, 2002, 682 с.

5. Видяпин И. Ю., Чеверев В. Г. Криосфера Земли, 2008, т. 12, № 4, c. 43-45.

6. Кудрявцев В. А., Ершов Э. Д., Чеверев В. Г. // Вестн. МГУ. Сер. Геология, 1973, № 5, с. 26-34.

7. Старостин Е. Г., Лебедев М. П. // Криосфера Зем$л и, 2014$, т. 18, № 3, № 4, c. 39-54. URL: http://www.izdatgeo.ru/pdf/krio/2014-3/46.pdf

8. Чеверев В. Г. // Криосфера Земли, 2003, т. 7, № 2, c. $30-34$.

9. Чеверев В. Г. // Криосфера Земли, 2006, т. 11, № 4, c. $25-26$.

10. Голубев В. Н., Влахова А. В., Ржаницын Г. А., Семенова И. В. // Криосфера Земли, 2018, т. 22, № 1, с. 20-26. DOI: https://doi.org/10.21782/kz1560-7496-2018-1(20-26) 
11. Zielke S. A., Bertram A. K., Patey G. N. // J. Phys. Chem. B, 2016, vol. 120, pp. 1726-1734. DOI: https://doi. org/10.1021/acs.jpcb.5b09052

12. Роман Л. Т., Мерзляков В. П., Малеева А. Н. // Криосфера Земли, 2017, т. 21, № 3, с. 24-31. DOI: https:// doi.org/10.21782/KZ1560-7496-2017-3(24-31)

13. Воронин А. Д. Основы физики почв. Учеб. пособие. М.: Изд-во Моск. ун-та, 1986, 244 с.

14. Шеин Е. В. Курс физики почв. Учебник. М.: Издво МГУ, 2005, 432 c.

15. Torrance J. K., Elliot T., Martin R. // Cold Regions Sci. and Technol., 2008, vol. 53 (1), pp. 75-82. DOI: https:// doi.org/10.1016/j.coldregions.2007.04.010

16. Shi Jie Chen, Shu Ping Zhao, Wei Ma, et al. // Sci. Cold and Arid Regions, 2014, vol. I, iss. 2, pp. 107-115.

17. Романенко К. А., Абросимов К. Н., Курчатова А. Н., Рогов В. В. // Криосфера Земли, 2017, т. 21, № 4, c. 75-81. DOI: https://doi.org/10.21782/KZ1560-74962017-4(75-81)

18. Истомин В. А., Чувилин Е. М., Буханов Б. А. // Криосфера Земли, 2017, т. 21, № 6, с. 134-139. DOI: https://doi.org/10.21782/KZ1560-7496-2017-6(134-139)

19. Istomin V. A., Chuvilin E. M., Bukhanov B. A., Uchida T. A. // Cold Regions Sci. and Technol., 2017, No. 137, pp. 60-67. DOI: https://doi.org/10.1016/j.coldregions.2017.02.005

20. Тягунин А. В., Копосов Г. Д. Механическая смесь гранулированного льда с песком. Тепловые и электрофизические свойства. Монография. LAP LAMBERT Academic Publishing GmbH \& Co. KG, 2012. 188 c.

21. Егочина В. И., Тягунин А. В., Булыгина А. В. // Физический вестник института естественных наук $и$ технологий САФУ. Сб. научн. тр., 2015, Вып. 14, с. 14-19.

22. Дерягин Б. В., Чураев Н. В., Муллер В. М. Поверхностные сильл. М.: Наука, 1985, 398 с.

\title{
INFLUENCE OF PHYSICAL CONDITIONS ON WATER TRANSITION FROM ICE SURFACE BY THE DISPERSION MEDIUM AT LOW TEMPERATURES
}

\author{
(C) 2018 V. I. Egochina G. D. Koposov, A. V. Tyagunin \\ Northern (Arctic) Federal University named after M. V. Lomonosov, \\ 17, Severnaya Dvina str., 163002 Arkhangelsk, Russia \\ e-mail: egochina.vi@mail.ru \\ Received 27.11.2018
}

\begin{abstract}
The purpose of the research was to test the possibility of using the ice surface as a generator of moisture in measuring the moisture conductivity of soils. The article presents the results of a study of the influence of various physical conditions on the moisture transition ice - dispersed medium at low temperatures. The experiments were carried out by weight method in the freezer with automatic temperature maintenance. To adjust the temperature, the freezer was equipped with a temperature sensor. Every day, readings of the mass of water transferred to the sample were obtained. The temperature range was chosen from -5 to $-24{ }^{\circ} \mathrm{C}$. The results of the study of the influence of factors such as: temperature, the presence of a temperature gradient in the direction of moisture transition, the effect of the gravitational field, the presence of impurities in the ice. Samples of the dispersed medium were selected inorganic: river sand, silica gel, white soot, kaolin (white) clay. $\mathrm{NaOH}, \mathrm{KOH}$ alkalis and $\mathrm{NaCl}$, $\mathrm{KCl}$ salts were used as impurities. Impurity concentration selected $(\%): 3.5,1,0.1,0.01$, and 0.001 . Two phases of the process of moisture transfer from the ice surface to the ground were identified: the first is associated with the movement of the diffusion flow; the second is associated with the transfer of moisture through the unfrozen water film. The driving force of the moisture flow is: gravitational action; temperature gradient and concentration gradient.

During the experiments, the influence of the selected factors on the moisture transfer of the ice dispersed medium was revealed: 1) the greater the temperature, the greater the probability that the water molecules will be able to move in a larger volume to the ground; 2) the presence of salt contributes to the process of moisture transfer due to a decrease in the surface tension coefficient; 3 ) when certain conditions are created, the moisture transfer is carried out in the opposite direction to the ice-sand contact.
\end{abstract}

Keywords: moisture transition, temperature gradient, gravitational action, sand, ice, quasi-liquid layer.

DOI: https://doi.org/10.17308/kcmf.2018.20/634 


\section{REFERENCES}

1. Novikov E. A., Shkuratnik V. L. Oshkin R. O. Earth's Cryosphere, 2016, vol. 20, no. 1, pp. 91-94. Available at: http://www.izdatgeo.ru/pdf/earth_cryo/2016-1/91_eng.pdf

2. Anderson D. M. The Interface Between Ice and Silicate Surface. CRREL, USA, March 1967, 31 p.

3. Kozlowski T. Cold Regions Sci. and Technol., 2016, no. 122 , pp. 18-25. DOI: https://doi.org/10.1016/j.coldregions.2015.10.009

4. Ershov E. D. Obshchaya Geokriologiya. Uchebnik [General Geocryology. Textbook] Moscow, Izd-vo MGU Publ., 2002, 682 p. (in Russ.)

5. Vidyapin I. Y., Cheverev V. G. Kriosfera Zemli [Earth's Cryosphere], 2008, vol. 12, no. 4, pp. 43-45. Available at: http://www.izdatgeo.ru/pdf/krio/2008-4/43.pdf (in Russ.)

6. Kudryavcev V. A., Ershov E. D., Cheverev V. G. Vestn. MGU. Ser. Geologiya, 1973, no. 5, pp. 26-34. (in Russ.)

7. Starostin E. G., Lebedev M. P. Kriosfera Zemli [Earth's Cryosphere], 2014, vol. 18, no. 3, pp. 46-54. Available at: http://www.izdatgeo.ru/pdf/krio/2014-3/46.pdf (in Russ.)

8. Cheverev V. G. Kriosfera Zemli [Earth's Cryosphere], 2003, vol. 7, no. 2, pp. 30-34. (in Russ.)

9. Cheverev V. G. Kriosfera Zemli [Earth's Cryosphere], 2006, vol. 11, no. 4, pp. 25-26. (in Russ.)

10. Golubev V. N., Vlaxova A. V., Rzhanicyn G. A., Semenova I. V. Kriosfera Zemli [Earth's Cryosphere], 2018, vol. 22, no. 1, pp. 20-26. DOI: https://doi.org/10.21782/ kz1560-7496-2018-1(20-26)

11. Zielke S. A., Bertram A. K., Patey G. N. J. Phys. Chem. B, 2016, vol. 120, pp. 1726-1734. DOI: https://doi. org/10.1021/acs.jpcb.5b09052
12. Roman L. T., Merzliakov V. Р., Малеева А. Н. Kriosfera Zemli [Earth's Cryosphere], 2017, vol. 21, no. 3, pp. 24-31. DOI: https://doi.org/10.21782/KZ1560-74962017-3(24-31)

13. Voronin A. D. Osnovy fiziki pochv: Ucheb. Posobie [Fundamentals of Soil Physics.] Moscow, Izd-vo Mosk. un-ta Publ., 1986, 244 p. (in Russ)

14. Shein E.V. Kurs fiziki pochv. Uchebnik [Soil Physics Course]. Moscow, Izd-vo MGU Publ., 2005. 432 p. (in Russ.)

15. Torrance J. K., Elliot T., Martin R. Cold Regions Sci. and Technol., 2008, vol. 53 (1), pp. 75-82. DOI: https:// doi.org/10.1016/j.coldregions.2007.04.010

16. Shi Jie Chen, Shu Ping Zhao, Wei Ma, et al. Sci. Cold and Arid Regions, 2014, vol. I, iss. 2, pp. 107-115.

17. Romanenko K. A., Abrosimov K. N., Kurchatova A. N., Rogov V. V. Kriosfera Zemli [Earth's Cryosphere], 2017, vol. 21, no. 4, pp. 75-81. DOI: https://doi.org/10.21782/ KZ1560-7496-2017-4(75-81)

18. Istomin V. A., Chuvilin E. M., Buxanov B. A. Kriosfera Zemli [Earth's Cryosphere], 2017, vol. 21, no. 6, pp. 134-139. DOI: https://doi.org/10.21782/KZ1560-74962017-6(134-139)

19. Istomin V. A., Chuvilin E. M., Bukhanov B. A., Uchida T. A. Cold Regions Sci. and Technol., 2017, no. 137, pp. 60-67. DOI: https://doi.org/10.1016/j.coldregions.2017.02.005

20. Tyagunin A. V., Koposov G. D. Mechanical Mixture of Granulated Ice With Sand. Thermal and Electrophysical Properties. Monograph. LAP LAMBERT Academic publishing $\mathrm{GmbH} \& \mathrm{Co} . \mathrm{KG}, 2012.188$ p. (in Russ.)

21. Egochina V. I., Tyagunin A. V., Byligina A. V. Fizicheskij vestnik instituta estestvennyh nauk i tekhnologij SAFU. Sb. nauchn. tr., 2015, vol. 14, pp. 14-19. (in Russ.)

22. Deryagin B. V., Churaev N. V., Muller V. M. Poverhnostnye sily [Surface forces]. Moscow, Nauka Publ., 1985, 398 p. (in Russ.)
Егочина Вероника Игоревна - аспирант Высшей школы естественных наук и технологий, Северный (Арктический) федеральный университет имени М. В. Ломоносова, Архангельск, Россия; еmail: egochina.vi@mail.ru

Тягунин Анатолий Вячеславович - к. ф.-м. н., доцент Высшей школы естественных наук и технологий, Северный (Арктический) федеральный университет имени М. В. Ломоносова, Архангельск, Россия; e-mail: alastor15@yandex.ru

Копосов Геннадий Дмитриевич - к. ф.-м. н., доцент Высшей школы естественных наук и технологий, Северный (Арктический) федеральный университет имени М. В. Ломоносова, Архангельск, Россия; e-mail: g.koposov@narfu.ru
Veronika I. Egochina - Postgraduate Student of the Graduate School of Science and Technology, Northern (Arctic) Federal University named after M. V. Lomonosov, Arkhangelsk, Russia; e-mail: egochina.vi@ mail.ru

Anatoly V. Tyagunin-Cand. Sci. (Phys.), Assistant Professor of the Graduate School of Science and Technology, Northern (Arctic) Federal University named after M. V. Lomonosov, Arkhangelsk, Russia; e-mail: alastor15@yandex.ru

Gennady D. Koposov - Cand. Sci. (Phys.), Assistant Professor of the Graduate School of Science and Technology, Northern (Arctic) Federal University named after M. V. Lomonosov, Arkhangelsk, Russia; e-mail: g.koposov@narfu.ru 